- Adults with Down Syndrome (DS) have particular oral health needs, requiring a supportive, empathic and well-informed dental team.

- Although most adults with DS in the study visit the dentist regularly, relatively little restorative treatment was provided.

- Experiences of oral care are influenced by the attitudes and skills of dental health professionals, and relatives' attitudes, preferences and knowledge.

- Relatives of adults with DS want more appropriate and timely oral health information from health care professionals.

- Current policy initiatives provide an opportunity for dentists to collaborate with other health and social care professionals to improve the provision of oral health care and information for people with DS.

\title{
Views and experiences of parents and siblings of adults with Down Syndrome regarding oral healthcare: a qualitative and quantitative study
}

\author{
P.L. Kaye, ${ }_{1}^{1}$ J. Fiske, ${ }^{2}$ E. J. Bower, ${ }^{3}$ J. T. Newton ${ }^{4}$ and M. Fenlon ${ }^{5}$
}

\begin{abstract}
Aims To investigate experiences and expectations of parents/siblings of adults with Down Syndrome (DS) regarding oral healthcare, and explore factors impacting on access and experience of dental care for this group. Design A two phase qualitative and quantitative study using in-depth interviews with a convenience sample of six parents/siblings, and a postal questionnaire of 200 parents/siblings of adults with DS who are members of the Down Syndrome Association.

Results The main themes elicited from the qualitative interviews related to concern, experiences, parents'/siblings' attitudes, preferences and information. The response rate from the postal questionnaire was 63.5\%. Adults with DS attended the dentist regularly but received little restorative treatment. Experience of oral healthcare was influenced by the attitudes and skills of dental health professionals; stigma; and relatives' expectations of dentists, their oral health beliefs, information and support received, knowledge and priorities. Parents/siblings wanted dentists to be proactive in providing more information on oral health issues in collaboration with other health and social care professionals. Conclusions Whilst most adults with DS visited the dentist regularly, relatively little treatment had been provided. Parents highlighted a need for appropriate and timely oral health information early in their child's life, and access to dentists who were sympathetic, good communicators and well-informed about DS.
\end{abstract}

\section{INTRODUCTION}

Down Syndrome (DS) is a genetic condition caused by a chromosomal abnormality and results in a characteristic appearance, learning disability and a variety of physical and medical features. ${ }^{1}$ There are approximately 60,000 people in the UK with the condition. ${ }^{2}$

People with disabilities have the right to equal standards of health and healthcare as the general population. ${ }^{3}$ However, there is evidence that they experience poorer oral health, have a greater unmet oral health need and less access to screening services than the general public. ${ }^{4}$ As the association between oral health and quality of life is well established, this situation may have wider implications. ${ }^{5,6}$

Studies indicate numerous user/carer barriers, professional service provider barriers and ethnic barriers to the oral health of people with learning disabilities (LD). ${ }^{4-16}$ In particular, oral health may be a low priority in the context of other social and medical challenges. ${ }^{4}$

Parents of individuals with LD can be isolated, not receiving the support and information necessary to enable them to access oral healthcare. It has been estimated that up to $25 \%$ of people with LD are unknown to statutory agencies until later in life when the parent becomes too frail to care for the individual. ${ }^{17}$

Prejudice, assumptions and negative stereotyping have led to attitudinal discrimination (or 'enacted stigma' ${ }^{18}$ ) by medical services towards individuals with disabilities. ${ }^{19}$ 'Felt stigma', the shame of being disabled or of having a child with disabilities and the fear of being discriminated against, has been shown to be even more disruptive of peoples' lives and well-being than the actual discrimination experienced. ${ }^{18}$

Studies investigating the oral health needs of people with LD indicate that they consistently have worse oral hygiene levels and a greater incidence of gingival inflammation and periodontal disease than that of the general population; yet they experience more untreated disease and more extractions. ${ }^{20-23}$ However, a recent study demonstrated a better clinical status for adults with LD than the general population although they had fewer teeth indicating that treatment is more likely to involve extraction of teeth. ${ }^{24}$ Whilst people with DS have an increased prevalence of periodontal disease compared with the general population and other people with learning disability, ${ }^{25}$ a carefully planned prevention programme can reduce its impact. ${ }^{26}$ 
Other studies have examined access issues, indicating that people with disabilities have problems in accessing oral health services and finding a dentist. ${ }^{12,27-29}$ However studies by Goldstein et $a l .{ }^{30}$ and Allison et al. ${ }^{29}$ demonstrated that once children with DS have found a suitable dentist they are more likely to attend regularly than their non-DS peers. Despite this, the latter study also showed that they are less likely to receive treatment than their non-DS peers. ${ }^{29}$

A number of recent policy documents detail the standards expected from health and social care professionals who care for people with LD. ${ }^{17,31}$ Clinical guidelines suggest that oral healthcare for people with LD can be improved through an integrated care approach. ${ }^{4}$ Such an approach not only recognises that people with LD are individuals with a right to participate in healthcare decisions, but also provides the necessary support to enable the individual to achieve and maintain oral health.

Most of the literature detailed thus far pertains to individuals with general LD. DS is a unique condition within the spectrum of $\mathrm{LD}$, and individuals with DS have a range of experience that differs from other groups with LD and the non-disabled population. ${ }^{1,2,32}$ Research on the oral healthcare experience of people with DS has focused on children and adolescents. ${ }^{15,26,29,30}$ There appears to be no literature specifically examining the experiences of adults with DS.

The aims of the study are to:

- investigate the views, experiences and expectations of parents/siblings of adults with DS regarding oral healthcare and

- describe factors impacting on access and experience of dental care for this group.

Throughout the paper, the terms 'parents/siblings' and 'relatives' will be used synonymously.

\section{METHOD}

The views and experiences of the parents/siblings of adult individuals with DS were investigated both qualitatively and quantitatively. The qualitative approach was particularly used to describe factors impacting on access and experience of dental healthcare, and the quantitative phase was used to investigate parents'/siblings' experiences and expectations of dental care for the adult with DS.

\section{Qualitative study}

Sample design and selection

In collaboration with the Camden Learning Disabilities Service, a convenience sample of six parents/siblings of individuals with DS aged 20 or over was identified. The relatives were the principle carers of the individual with DS.

Letters explaining the purpose of the study and inviting the relatives to be interviewed were sent and followed up by telephone calls to confirm agreement to participate in the study.

\section{Data collection}

All the parents/siblings were interviewed in their own homes between December 2000 and January 2001 by one researcher. The purpose and method of the study was explained and an assurance of complete confidentiality and anonymity was given. Participants were invited to ask any questions regarding the purposes of the study before signing a written consent form.

The interviews were reflexive, the interviewer exploring topics raised by the participants who were encouraged to speak freely about their feelings, experiences, beliefs and concerns regarding oral health and healthcare for the adult with DS in their care. A topic guide was used to ensure all areas of interest to the researcher were explored. The interviews were recorded on audio-tape.

\section{Data analysis}

All the interviews were transcribed verbatim and then analysed by three researchers to minimise interpretation bias in identifying common themes from the participants' speech. The themes represented key issues and concepts raised by the respondents and also reflected the aims and objectives of the study. Using the 'Framework' analytic method, ${ }^{33}$ the themes were assembled into a detailed numerical index which was applied systematically to all the transcripts. Coding the data in this way allows the researcher to identify the presence of a particular theme in a transcript. A matrix of themes and respondents was compiled and used to map the range and nature of phenomena, and identify associations between themes with a view to providing explanations for the findings. A useful summary of the 'Framework' method is found in Pope et al. ${ }^{34}$

\section{Quantitative study}

\section{Questionnaire development}

Using data from the qualitative study and the evidence base in this area, a 32-item structured questionnaire was designed to investigate parents'/siblings' experiences and expectations of dental care for the adult with DS. The questionnaire included sections covering the following areas:

- Demographic characteristics of respondent

- Expressions of concern regarding oral health

- Access to dental services

- Experience of dental treatment

- Desirable qualities of dentists

- Information requirements.

The questionnaire was piloted amongst the six relatives who took part in the qualitative study to ensure clarity. No amendments to the questionnaire were required.

\section{Questionnaire distribution}

Following contact with the Down Syndrome Association (DSA), 200 members of the association who are parents or siblings of adults with DS aged 20 or over were randomly selected from the 2,066 DSA members in this age group. The sample size was negotiated with the DSA who funded and administered the distribution of the questionnaires. There are no comprehensive data on the prevalence of DS in the UK, and it is not known what proportion of the estimated 60,000 people with DS living in the $\mathrm{UK}^{2}$ are adults.

A questionnaire, reply-paid envelope and an information letter were sent to the parents/siblings in the spring of 2001. The relatives were informed that their responses would be confidential. As a condition of its involvement, the DSA distributed and collected the questionnaires to ensure the confidentiality of its members and thus it was not possible to arrange a follow-up mailing to improve the response rate.

\section{Data analysis}

The data were entered onto an Excel spreadsheet and analysis was limited to descriptive statistics.

\section{Ethical approval}

Ethical approval for the study was granted by the Guy's Research Ethics Committee and the Local Research Ethics Committee of Camden and Islington Community Health Services NHS Trust.

\section{RESULTS}

\section{QUALITATIVE DATA}

The participants comprised six relatives - four mothers, one father and one sibling - of adults with DS. The demographic characteristics of the participants are shown in Table 1. Interviews lasted between 40 and 45 minutes. 


\begin{tabular}{|c|c|c|c|c|c|c|}
\hline Participant & $\mathrm{P} 1$ & $\mathrm{P} 2$ & P3 & P4 & P5 & P6 \\
\hline $\begin{array}{l}\text { Relationship } \\
\text { to adult } \\
\text { with DS }\end{array}$ & Mother & Mother & Father & Mother & Brother & Mother \\
\hline $\begin{array}{l}\text { Sex of adult } \\
\text { with DS }\end{array}$ & Male & Male & Male & Female & Male & Male \\
\hline $\begin{array}{l}\text { Age of adult } \\
\text { with DS }\end{array}$ & 29 & 29 & 37 & 24 & 36 & 33 \\
\hline $\begin{array}{l}\text { Living } \\
\text { arrangement } \\
\text { of adult } \\
\text { with DS }\end{array}$ & $\begin{array}{l}\text { Parental } \\
\text { shome }\end{array}$ & $\begin{array}{l}\text { Parental } \\
\text { home }\end{array}$ & $\begin{array}{l}\text { Parental } \\
\text { home }\end{array}$ & $\begin{array}{l}\text { Parental } \\
\text { home }\end{array}$ & $\begin{array}{l}\text { Parental } \\
\text { home }\end{array}$ & $\begin{array}{l}\text { Community } \\
\text { care home }\end{array}$ \\
\hline Ethnic group & White & White & White & White & Greek & White \\
\hline
\end{tabular}

Themes and sub-themes explored by the researcher and emerging from the data included:

- Expressions of concern regarding oral health

- Experiences of dental care:

- Attitudes and skills of dental health professionals

- Feelings of stigma

- Relatives' attitudes:

- Expectations of healthcare professionals

- Perception of dentists' ability to manage behavioural problems

- Oral health beliefs

- Priorities

- Preferences of the individual with DS

- Information:

- Support from health and social care professionals

- Information requirements

\section{Expressions of concern regarding oral health}

Four of the parents/siblings felt that the adult in their care had unmet oral health needs although three of these adults were being taken to the dentist regularly:

'When he's biting on hard things, he won't eat it because his teeth hurt or his gums hurt, he won't eat it. You know, things like cutlets, when you gnaw at the bone, he won't...he won't even attempt that anymore. Eating on an apple, he doesn't like doing that either.' (P6)

Some of the participants expressed concern about maintaining adequate oral hygiene, and mentioned specific oral problems such as bleeding gums, delayed tooth eruption and caries. Poor periodontal condition (indicated by bleeding and recession) was of particular concern because of its link with tooth loss in DS:

'[My] main concerns are oral hygiene...it's just that I'm constantly cleaning his teeth, you know, so I think that every parent of a Down Syndrome [child] should have a course in oral hygiene' (P2).

\section{Experience of dental care}

Four of the individuals with DS were attending the dentist regularly (at least once a year). One individual had never been to the dentist and the other had received no dental care since the age of 14 . All the participants who wanted to find a dentist for the adult with DS had been able to access care. However, they did highlight the importance of easy access and close proximity. They also felt that a list of names and telephone numbers of dentists specialised or interested in treating people with DS would be extremely useful.

\section{Attitudes and skills of dental health professionals}

Parents/siblings expressed very different opinions regarding the attitudes and skills of the dental health professionals they encountered. Some felt they had received excellent care from a sympathetic and skilful dentist:
'It's taken up a long time to build that confidence with the dentist...she's lovely, no problem. She's fantastic. Really, really nice. He's had a couple of fillings...he's had extractions as well.' (P6)

Others were more critical. This mother is describing her experience of attending a maxillofacial clinic two years' previously with her daughter:

'She was getting a very sore tongue. I did try to say to them that T. was getting the sore tongue at other times other than biting her tongue. And I felt that I really wasn't being listened to in that respect. I didn't feel that there was enough advice or there wasn't the will to actually look into it further.' (P4)

The participants were clear about the qualities they wanted the dentist treating the individual with DS to possess. Good communication (including talking directly to the person with DS, being warm and friendly and explaining things) was considered imperative:

'Well, someone that would talk to A. and not to me. You know, first off they talk to A, hello how are you...' (P6)

Stigma

All the mothers interviewed expressed strongly the stigma of having a child with DS. The stigma was expressed by the way the relative labelled DS, narrated experiences of shame, and the shift from the first to the second or third person in the conversation: 'I think one of the things that happens with mums of Downs babies is that they don't want to show them off at clinic. Mothers go to health clinics after that baby is born to show off their beautiful baby and how well he's doing...but mothers with Downs babies don't want to do that, they're embarrassed. They find it difficult.' (P2)

However, whilst this appeared to be a barrier to care in the early years of the child's life, felt stigma was not a barrier to accessing dental care as an adult with the relatives actively seeking the most appropriate care for their son or daughter.

There was some evidence of enacted stigma:

'The treatment he's got from dentists regularly is perfunctory, you know, not particularly concerned about the growth of teeth when he was younger. The gums have receded so much that I don't think...well I'd be advised...nobody seems particularly interested in doing anything about it...because they're Downs children... They don't feel that they are... I got the impression that they didn't feel that they were worth the effort.' (P2)

However, other participants were happy with the inclusive approach taken by the dentist:

'She talks to him, saying have you been cleaning your teeth? She used to let him try the drills and this, I'm going to do this A. on your cheek...and she did that with the other children, my other two boys as well.' (P6)

\section{Relatives' attitudes}

Expectations of health care professionals

There were large variations in the expectations of dental professionals with some parents/siblings expecting information, time, and expert care for the individual in their care:

'I did feel perhaps [the dentist] could have cleaned T.'s teeth. This was the second time. The first time he prepared her by saying next time I'm going to clean your teeth, but then next time...he spent a couple of minutes cleaning them, and because she sort of...she wasn't used to it and he said oh OK that's fine and left her...but I thought well that's a shame now because, you know, why can't we just have another go at getting them all cleaned properly. Now she's got to wait 6 months now before he attempts to clean them again...why have I got to wait another 6 months?' (P4) 
Such relatives had all moved the adult in their care to another dentist in order to access the dental care they felt was most appropriate. Others had much lower expectations:

'He's had a bit of bother with a loose tooth here and there...I don't know whether they've done anything about it but it seems to be all right now... [the dentist] is good, he's experienced and he knows what he's talking about obviously...I don't think there's a need to have dietary advice is there? From a dentist? I don't think that's their job to do that to be honest.' (P5)

\section{Behavioural problems}

Parents/siblings recognised that behavioural problems could limit dental treatment. Whilst most of the relatives sought dental care in spite of behavioural difficulties, this parent had never taken his son to the dentist as he perceived that his son's behavioural problems would be unmanageable:

'He won't let you look...I tell you now, nobody will ever do anything to [the broken tooth]. Nobody. I don't think it would make any difference whatever what the dentist was like. I think it would be with an angel from the Lord, W. won't let him look at his mouth.' (P3)

\section{Oral health beliefs}

There was a strong association between the relatives' oral health beliefs and the dental care received by the adult with DS. Where the carer held a preventive philosophy, the adult with DS attended the dentist regularly and the carer was more likely to clean the individual's teeth themselves:

'I do worry about her teeth because I'm worried about gum disease, that you know, I'm not cleaning her teeth properly. From my own experience, that if I don't wash my teeth properly, my dentist is always saying to me about gum disease.' (P4)

However, others either did not consider treatment necessary or believed it could be detrimental and felt that it was only required if the individual with DS had pain:

'I never gave much thought to it, because he never seemed to get any trouble.' (P3)

'D. does not have a dentist. I can tell this, I don't believe in dentists, I think they ruin your teeth. Don't get me wrong, if he was in pain, he'd go. But he's never had any problems and I look at them and there's nothing there. I'll take him when I need to take him.' (P1)

\section{Priorities}

Judgements about what was most important for themselves and for the adult in their care were expressed by all the participants. The promotion of social development, the needs of other siblings, and other healthcare issues such as foot and eye care, were explained as being more important than oral healthcare at that time:

'You have to prioritise which is the most important thing. At the moment I am prioritising the feet as being the most important because if she becomes less mobile that's more of a problem.' (P4)

\section{Preferences of the individual with DS}

In most cases, the individual with DS was described as a passive recipient of health services and there was little indication of the individual's wishes or having them acknowledged. However, this relative was aware of his brother's wishes not to attend the dentist: He's not brilliant. But you know he goes. He's like any child I guess in that he's, you know, doesn't like it. There is perhaps a little bit of apprehension about it, I'm not sure. He might say oh I don't really want to go. Well at least he's honest about it. He doesn't sort of bottle it up. So in that respect, yea he's open about it.' (P5)
The conflict between the need to maintain oral health yet encourage personal autonomy is articulated by this parent: 'Although in his house they try and let him decide for himself what he wants to do, I think it's taken a little while for them to realise that, you know, they've got to look at his mouth and say sorry A. go upstairs and clean your teeth. I mean, he's 33, you know, how do you tell a 33-year-old man to go and clean his teeth because he hasn't done them.' (P6)

\section{Information}

Support from health and social care professionals

All the parents stated that in the early years of the child's life they had spoken to other parents, contacted voluntary organisations and read books to discover general healthcare information. They had received little information from healthcare professionals:

'When I had D., I stayed in hospital; 'home you go' and that was it. No one ever came near me. Just had to sort of cope, you know.' (P1)

'I'm not criticising professionals in...but sometimes the information is lacking because they don't know themselves, so I don't know whose fault that is...their training or whatever.' (P5)

Whilst the situation had improved over the years, all the participants indicated that they had received very little oral healthcare information from general health and social care professionals, or from voluntary organisations such as Mencap:

'You're the first person [the researcher] I've seen since he's been 14 , and even mentioned teeth to me.' (P1)

Information from dentists was better but varied widely with most relatives receiving oral hygiene instruction, some receiving caries prevention advice and none receiving information about other dental problems associated with DS such as swallowing and chewing problems, hypodontia and microdontia:

'...but the other thing I've discovered recently...is that she's still got some baby teeth, and I didn't realise that, and it made me wonder what else am I not aware of?' (P4)

\section{Information requirements}

All the participants indicated that they would welcome more information but this parent highlighted the importance of the need for sensitivity in giving information and picking the right moment: 'You see, what happens in the first couple of years with parents who've got Downs children is they have a lot of leaflets thrust at them, and they don't want to look at them. They're not interested. They're so preoccupied with the despair and the grief about the baby that they've got that they're not going to look at leaflets...' (P2)

Relatives also wanted to receive information without having to ask for it:

'They've got to volunteer the information more, rather than wait for you to ask them, because sometimes you don't know what you should be looking for really.' (P4)

Whilst all the participants felt that a leaflet for carers detailing information on oral healthcare needs of people with DS and guidance on accessing dental services may be useful, several parents/siblings preferred a healthcare professional to give them information in person:

'... a leaflet on dentistry...I think it would only be useful if it was in conjunction with everything else...I'm gonna put that away in a drawer and forget about it. I think you need someone, a paediatrician that you can readily go to see and, even if you got that appointment once a year.' (P4) 


\section{QUANTITATIVE STUDY}

\section{Characteristics of the respondents}

Replies were received from 127 of the 200 parents/siblings (response rate 63.5\%). Although a number of the questionnaires were incomplete, the data they contained were considered useful and included in the analysis of the results. Ninety-five per cent of respondents were female and $85 \%$ of respondents were aged between 50-69 years. Ninety-eight per cent of respondents were parents of an adult with DS and 2\% were siblings.

Eighty-nine per cent of the individuals with DS were aged between $20-29$ years, $10 \%$ were aged between $30-39$ years and $1 \%$ was aged between 40-49 years. Forty-six per cent were male and $54 \%$ were female.

\section{Access to dental services}

Of the adults with DS, 117 (92\%) were registered with a dentist and $114(90 \%)$ attended regularly (at least once a year). This reflects the dental attendance of their relatives of whom 113 (88\%) were also attending regularly. Only 4 (3\%) parents/siblings indicated difficulty in finding an appropriate dentist. Seventythree (57.5\%) of the individuals with DS were attending their relative's dentist, and 45 (35\%) had received dental treatment from a 'specialist' on one or more occasion.

\section{Experience of dental treatment}

Details of treatment received are shown in Table 2. Thirty-eight per cent and 33\% of the adults with DS had experienced extractions and restorations respectively. With the exception of oral hygiene instruction, levels of other preventive interventions (such as fluoride therapy and fissure sealing) were minimal.

Ninety-one per cent (116) of parents/siblings felt that the treatment received by the individuals with DS had been appropriate. Similarly, 108 (85\%) respondents felt that the dentist was friendly although rather less $(84,66 \%)$ felt that the dentist was enthusiastic in treating the individual with DS. Only five parents/siblings (4\%) felt that the treatment given was inappropriate, citing a lack of confidence on the part of the dentist and a lack of information received.

\section{Expressions of concern about oral health}

Concerns about oral health of the adult with DS are detailed in Figure 1. In spite of the high levels of dental attendance of the adult with DS, 83 (65\%) parents/siblings were concerned about ongoing oral disease (periodontal disease, caries and oral infections), and 99 (78\%) were concerned about one or more aspects of oral health (excluding oral hygiene).

Table 2 Reported dental treatment experience of adults with DS

\begin{tabular}{lc}
\hline Treatment received & Number of adults with DS (\%)* \\
\hline Oral hygiene instruction & $92(72.5 \%)$ \\
\hline Dietary advice & $16(12.5 \%)$ \\
\hline Fillings & $41(32 \%)$ \\
\hline Tooth extractions & $46(38.5 \%)$ \\
\hline Dentures & $6(4.5 \%)$ \\
\hline Tooth cleaning & $92(72.5 \%)$ \\
\hline Fissure sealants & $5(4 \%)$ \\
\hline Fluoride therapy & $4(3 \%)$ \\
\hline Crowns & $1(1 \%)$ \\
\hline Bleaching & $1(1 \%)$ \\
\hline Orthodontics & $8(6.5 \%)$ \\
\hline No treatment received & $2(1.5 \%)$ \\
\hline Treatment received but no prevention & $27(21 \%)$ \\
\hline advice reported & \\
\hline * Respondents could report more than one treatment so percentages do not total 100.
\end{tabular}

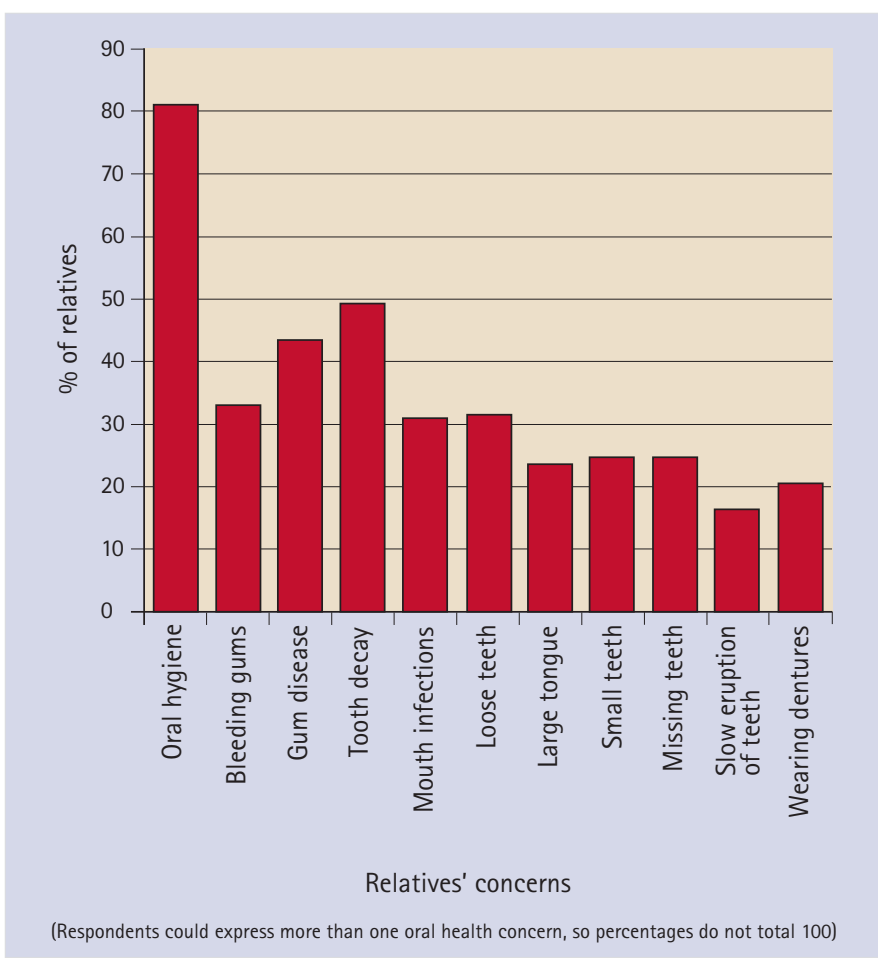

Fig. 1 Concerns regarding the oral health of the adult with DS

One hundred and three (81\%) respondents also expressed concerns regarding prevention issues such as maintaining oral hygiene due to poor manual dexterity although only 17 (13\%) always assisted the individual with DS in cleaning their teeth.

\section{Desirable qualities of dentists}

Ninety per cent (114) of respondents desired qualities which relate to building good rapport such as being sympathetic, patient, gentle, explaining procedures before treatment and involving the adult with DS in the conversation. Almost all the respondents felt the dentist should understand about DS (120, 94.5\%) but less relatives felt that the dentist should be specialised or experienced in treating people with DS (70, 55\% and $77,60.5 \%$ respectively).

\section{Information}

Only $27(21 \%)$ respondents indicated that a social or healthcare professional had suggested that they take the individual in their care to the dentist. Furthermore, only 61 (47.5\%) parents/siblings felt that they had received adequate information on the various health services available.

Relatives felt that speaking to other parents of people with DS $(72,56.5 \%)$ and contacting charity organisations $(76,60 \%)$ were the most useful ways of learning about DS itself and appropriate health services. Asking health professionals was felt to be useful by only 37 (29\%) respondents (Fig. 2).

Most relatives $(98,76 \%)$ felt that it would be helpful to have a leaflet providing advice on the oral health issues associated with DS, and 98 (76\%) felt information should be made available before and/or during the eruption of deciduous teeth. Respondents felt that information on oral problems associated with DS $(117,92 \%)$ and oral hygiene advice $(118,93 \%)$ were the most important types of information required, although information on a wide range of oral health and treatment issues was requested.

There was a consensus that a leaflet should be available in doctors' surgeries $(118,93 \%)$, local health centres $(115,90.5 \%)$ and dental surgeries $(114,90 \%)$. However relatives also suggested a wide range of public places and a number of public and voluntary 


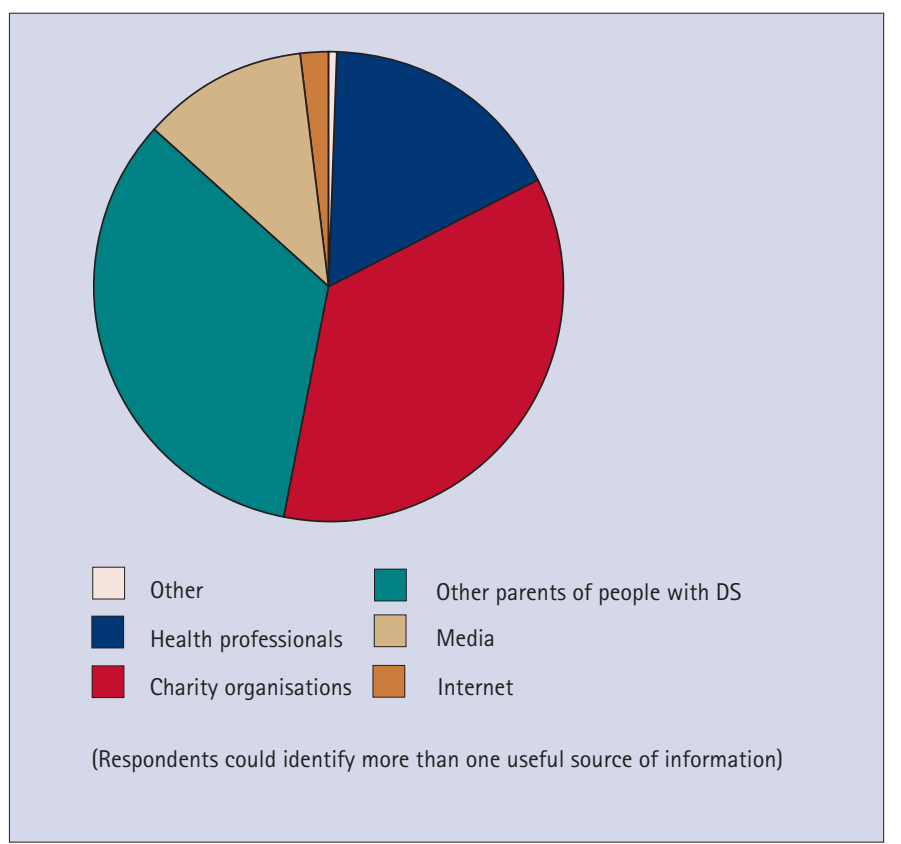

Fig. 2 Most useful sources of learning about DS

organisations where leaflets should be made available, indicating the need to broaden access to information.

\section{DISCUSSION}

This paper reports the findings of a qualitative and quantitative study of the views, experiences and expectations of parents/ siblings of adults with DS regarding oral healthcare, and factors impacting on access to dental care for this group. The implications of its findings are of particular importance as it is estimated that up to $80 \%$ of adults with DS now live to 55 years of age or over. ${ }^{35}$

The qualitative results allowed the identification of themes and sub-themes that formed the basis for the questionnaire development used later in the study. Although only six relatives were

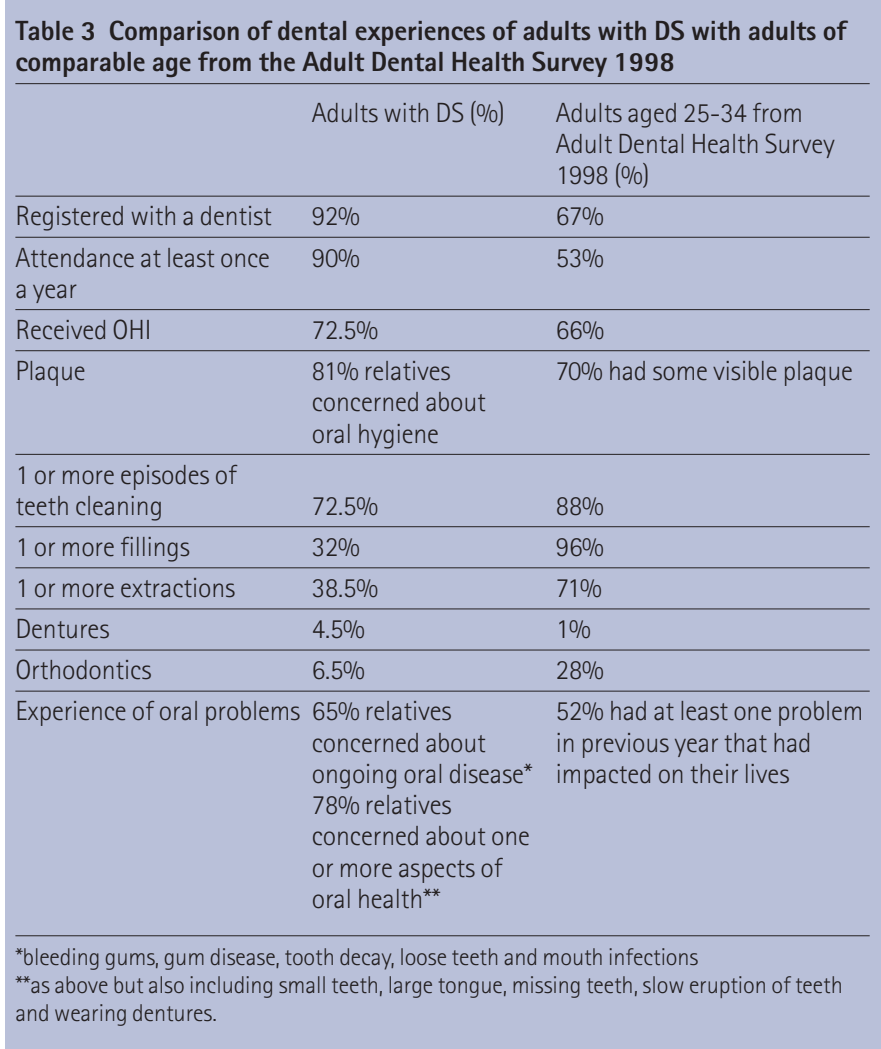

interviewed, they came from a variety of backgrounds and had a spectrum of oral health beliefs and different experiences of oral healthcare. Moreover, by the conclusion of the final interview there appeared to be no additional themes emerging. Rigorous methodological procedures detailed above were implemented to improve reliability and validity.

The high dental registration levels, regular attendance at the dentist and satisfaction with treatment received, reported in the quantitative data, are extremely encouraging. However, caution should be exercised when interpreting the results as other studies of people with LD have reported problems in accessing oral health services, ${ }^{12,27-29}$ although the study by Allison et $a{ }^{29}$ was conducted in France and the other studies were published more than a decade ago before the Disability Discrimination Act $(1995)^{3}$ came into effect. It could also be argued that members of the DSA are not representative of all relatives of adults with DS as they are probably the most motivated of such parents/siblings. Therefore, they are more likely to be aware of the needs and rights of the adult in their care. It is very difficult to obtain a representative sample of adults with DS as there is no national database and not all adults with DS are known to social services. Furthermore, the sample size was small in relation to the likely number of the adults with DS in the UK, also threatening the validity of the findings. It was not possible to arrange a second mailing to improve the response rate, although a response rate of between $60-70 \%$ is regarded as normal for postal questionnaire surveys and it is reasonable to present the results as representative of the views of the target group. ${ }^{36} \mathrm{Howev-}$ er, the non-respondents are more likely to be people who were not interested in and/or did not use dental services, introducing a positive bias into the results. Thus interpretation of the quantitative data should be carried out on the basis that this is the best scenario.

Keeping the possible bias in mind, it is still interesting to compare the findings of the current study with similar aspects of the 1998 Adult Dental Health Survey (ADHS). ${ }^{37}$ The registration and attendance levels of the adults with DS in the current study were markedly higher than for similarly aged adults in the ADHS (Table 3). Yet when comparing treatment experience, adults with DS had received far fewer restorations, extractions and orthodontic treatment, and slightly less tooth cleaning, but a greater proportion had dentures. However, satisfaction levels of adults in the ADHS were far lower than that of the respondents in this study, with $21 \%$ indicating that they wished to change dentist.

Many of the parents/siblings expressed concerns regarding the oral health of the adult with DS in their care, indicating a higher level of unmet oral health need than adults from the ADHS despite a greater regularity of dental attendance (Table 3), a finding shared by Allison et al. $^{29}$ Some caution should be exercised in interpreting this finding as the two studies did not use exactly the same instrument to measure oral health need. Nonetheless, there are clear differences in treatment received. Whilst the differences in placement of restorations could be attributed to the lower caries rate of people with DS, ${ }^{38-39}$ one might have similarly expected evidence of more periodontal therapy and orthodontics given the higher incidence of these problems in this population. ${ }^{25,38-41}$ Clearly, there are other contributory factors relating to treatment provision.

The study suggests that a number of different factors may influence experiences of oral healthcare. These include the attitudes and skills of dental health professionals, behavioural problems, feelings of stigma, and the relatives' expectations of dentists, their oral health beliefs, information and support received, and their knowledge and priorities. Similar factors are mentioned in other studies of people with learning disabilities., ${ }^{4,-16}$

Providing quality dental care to individuals with DS requires a supportive, skilled dental team, ${ }^{32}$ together with time and patience. In this study the majority of individuals with DS were being treated in general practice where the current NHS system of 
remuneration tends to dissuade dentists from spending the extra time necessary for good communication and behaviour management. Current proposals to change the ways dental services are commissioned and remunerated ${ }^{42-43}$ may impact favourably on the time and services made available for adults with DS. Other studies have demonstrated a lack of confidence amongst dentists in treating and managing people with special care needs ${ }^{10}$ and an ambivalence towards treating them in general practice. ${ }^{16}$

Due to the influence of relatives' attitudes, beliefs and expectations on the oral healthcare received by individuals with DS it is important that an empathic and supportive dental team positively engages with parents when the child is very young in order to instigate strategies to prevent/minimise dental disease. ${ }^{32}$ With the exception of oral hygiene instruction, levels of other preventive interventions provided for the adults in this study were minimal. Furthermore, most of the respondents had not received encouragement from health and social care professionals to take their young child to the dentist, impacting negatively on the ability of some of the adults with DS to receive treatment now.

Whilst one might assume that attitudes and practices have changed in the last twenty years, a recent survey by the DSA suggests that some medical staff are failing to adhere to existing guidelines and that their prejudice and ignorance is impacting on the medical care that people with DS are offered. ${ }^{19}$

It is apparent that there has been and still is a considerable lack of information given to parents about oral health issues pertaining to DS from dentists as well as from other health and social care staff. Whilst most relatives felt that leaflets would be helpful and should be made available from a variety of sources, this and other studies indicate that it is important that parents are also supported by concerned health professionals who are sensitive enough to give appropriate and timely information. ${ }^{44}$

A number of government policy documents relate to people with DS, the most recent being the white paper 'Valuing People' which seeks amongst other things, improvements in health for people with LD. ${ }^{17}$ It states that through an integrated approach to services and a focus on the whole person, people with LD should be able to: 'access a health service designed around their individual needs, with fast and convenient care delivered to a consistently high standard and with additional support where necessary' ( $p 125)$

Additionally, all people with LD who use publicly funded services should now have a named care manager to act as their service co-ordinator. Health facilitators are being appointed from each local community learning disability team to support people with LD to access appropriate healthcare. The Department of Health target is for all people with LD to be registered with a GP by June 2004 and to have a personalised 'health action plan' by June 2005. Whilst 'Valuing People' states that health action plans should include oral health and dental care, the examples given in a more recent Department of Health implementation document ${ }^{31}$ barely mention these areas. Consequently, there is still a danger that oral healthcare will continue to be overlooked by health and social care staff as it clearly has been according to the findings of this study.

Both 'Valuing People' and 'Clinical Guidelines and Integrated Care Pathways for the Oral Health of People with Learning Disabilities' ${ }^{4}$ call for an integrated multi-disciplinary approach to caring for people with LD. Providing high quality dental care for an individual with DS may involve working across professional boundaries and actively liaising with their health facilitator to ensure that oral health is kept on the healthcare agenda. Parents/siblings in the current study clearly expect dentists to actively collaborate with other health and social care professionals in providing information about oral healthcare.

'Valuing People' also states explicitly that people with LD are expected to have choice and control over their lives and it is no longer acceptable for organisations to view people with disabilities as passive recipients of services. Paradoxically, in this study, most of the relatives interviewed regarded the adult in their care as a passive recipient of services and when the individual expressed a desire not to have dental treatment their wishes were over-ruled. On the other hand, this could be a reflection of the relative's expert knowledge of the individual's capacity to understand and make informed choices, balanced against the relative's value of the importance of good oral health. The dilemma of trying to encourage choice and control, yet ensuring that oral health is maintained is one that is faced by all carers and healthcare professionals treating people with LD.

\section{CONCLUSIONS}

There appears to be few problems experienced by parents/siblings in finding a dentist for the adult with DS in their care. However, their views and experiences of dental care vary and are influenced by a number of factors, including the relatives' concerns and experiences regarding oral health, the information and advice provided, and the attitudes and qualities of healthcare professionals. Dentists are important but sometimes forgotten members of the multidisciplinary team providing care for adults with DS. Current policy initiatives provide an opportunity for dentists to collaborate actively with other health and social care professionals to improve the provision of information about oral health for people with DS.

The authors are particularly grateful to the Down Syndrome Association for their support in questionnaire distribution, and to the Camden Learning Disabilities Service for their part in organising the interviews. The authors would also like to thank all the parents and relatives who took part in the study.

1. Roizen N, Patterson D. Downs Syndrome. Lancet 2003; 361: 1281-1289.

2. Downs Syndrome Association. Key facts and figures. Available from http://www. downs-syndrome.org.uk/DSA_detBackground.aspx?ba=3 2003. [accessed 16.6.03]

3. Her Majesty's Stationary Office. Disability Discrimination Act (c.50) London: HMSO 1995.

4. The Faculty of Dental Surgery of the Royal College of Surgeons of England and The British Society for Disability and Oral Health. Clinical guidelines and integrated care pathways for the oral health of people with learning disabilities. London: Royal College of Surgeons of England, 2001.

5. Locker D. The burden of oral disorders in populations of older adults. Community Dent Health 1992; 9: 109-124.

6. McGrath C, Bedi R. A study of the impact of oral health on the quality of life of older people in the UK - findings from a national survey. Gerodontol 1998; 15: 93-98.

7. Hennequin $M$, Faulks D, Veyrune J L, Bourdiol P. Significance of oral health in persons with Down Syndrome: a literature review. Dev Med Child Neurol 1999; 41: 275-283.

8. McDermott R E, Elbadrawy H E. A survey of parents perceptions of the dental needs of their handicapped child. Can Dent Assoc 1986; 52: 425-427.

9. Davies K W, Holloway $\mathrm{P} J$, Worthington H V. Dental treatment for mentally handicapped adults in general practice: parents and dentists' views. Comm Dent Health 1988; 5: 381-387

10. Matthews R W, Porter S R, Scully C. Measurement of confidence levels of new UK dental graduates: an approach to academic audit. Int Dent J 1993:43: 606-608.

11. Gordon S M, Dionne R A, Snyder J. Dental fear and anxiety as a barrier to accessing oral health care among patients with special health care needs. Spec Care Dent 1998 18: 88-92.

12. Wilson K I. Treatment accessibility for physically and mentally handicapped people a review of the literature. Comm Dent Health 1992; 9: 187-192.

13. Williams S A, Godson J H, Ahmed I A. Dentists' perceptions of difficulties encountered in providing dental care for British Asians. Comm Dent Health 1995; 12: $30-34$

14. Band R. The NHS - Health for All? People with learning disabilities and health care London: Mencap, 1998.

15. Allison PJ, Faulks D, Hennequin M. Dentist-related barriers to treatment in a group of individuals with Down syndrome in France: implications for dental education. Disabil Oral Health 2001; 2: 18-26.

16. Bedi R, Champion J, Horn R. Attitudes of the dental team to the provision of care for people with learning disabilities. Spec Care Dent 2001; 21:147-152.

17. Department of Health. Valuing people: a new strategy for learning disability for the $21^{\text {st }}$ Century. London: Department of Health, 2001.

18. Scambler G, Hopkins A. Being epileptic: coming to terms with stigma. Sociol Health IIIn 1988: 8: 26-43.

19. Rutter S, Seyman S. 'He'll never join the army.' A report on a Downs Syndrome Association survey into attitudes to people with Downs Syndrome amongst medical professionals. London: Downs Syndrome Association, 1999.

20. Nunn J H. The dental health of mentally and physically handicapped children: review of the literature. Commun Dent Health 1987; 4: 157-168. 
21. Shyma M, Al-Mutawa, Honkala S, Sugathan T, Honkala E. Oral hygiene and periodontal conditions in special needs children and young adults in Kuwait. J Disabil Oral Health 2000; 1: 13-19.

22. Francis J R, Stevenson D R, Palmer J D. Dental health and dental care requirements for young handicapped adults in Wessex. Comm Dent Health 1991; 8:131-137.

23. Gizani S, Declerck D, Vinckier F, Martens L, Marks L, Goffin G. Oral health condition of 12-year-old handicapped children in Flanders (Belgium). Comm Dent Oral Epidemiol 1997; 25: 352-357.

24. Naidu R S, Pratelli P, Robinson P G, Gelbier S. The oral health and treatment needs of adults with a learning disability living in private households in Lambeth, Southwark and Lewisham, London. J Disabil Oral Health 2001; 2: 78-82.

25. Reuland N, Dijk J. Periodontal disease in Down Syndrome - a review. J Clin Periodonto/ 1986; 13: 64-73.

26. Shapiro J, Stabholz A. A comprehensive 30-month preventative dental health program in a pre-adolescent population with Downs Syndrome: A longitudinal study. Spec Care Dent 1996; 16:33-37.

27. Finger S T, Jedrychowski J R. Parents perception of access to dental care for children with handicapping conditions. Spec Care Dent 1989; 9: 195-199.

28. Lo G L, Soh G, Vignehsa H, Chellappah N K. Dental service utilisation of disabled children. Spec Care Dentistry 1991; 11: 194-196.

29. Allison P J, Hennequin M, Faulks D. Dental care access among individuals with Down Syndrome in France. Spec Care Dent 2000; 20: 28-34.

30. Goldstein H. Utilization of health services over a one-year period by an adolescent population with Down Syndrome. Danish Med Bull 1988; 35: 585-588.

31. Department of Health. Action for Health - health action plans and health facilitation. London: Department of Health, 2002.
32. Fiske J, Shafik H. Downs Syndrome and oral care. Dent Update 2001; 28: 148-156.

33. Richie J, Spencer L. Qualitative data analysis for applied policy research. In Bryman A, Burgess R (ed) Analyzing Qualitative Data. London: Routledge, 1994.

34. Pope C, Ziebland S, Mays N. Qualitative research in health care. Analysing qualitative data. BrMed J 2000; 320: 114-116.

35. Nadel L, Rosenthal D. Down Syndrome: living and learning in the community. New York: Wiley-Liss, 1995.

36. Sjostrom 0 , Holst $D$, Lind $S \mathrm{O}$. Validity of a questionnaire survey: the role of nonresponse and incorrect answers. Acta Odontol Scand 1999; 57: 242-245.

37. Kelly M, Steele J G, Nuttall N et al. Adult Dental Health Survey: Oral Health in the United Kingdom in 1998. London: Her Majesty's Stationary Office, 2000.

38. Ulseth J O, Hestnes A, Stovner L J, Storhaug K. Dental caries and periodontitis in persons with Down Syndrome. Spec Care Dent 1991; 11:71-73.

39. Desai S S. Down Syndrome: A review of the literature. Oral Surg, Oral Med, Oral Pathol, Oral Radiol Endod 1997; 84: 279-285.

40. Sassouni V, Forrest E. Dentofacial pathology related to malocclusion: orthodontics in dental practice. St. Louis: CV Mosby, 1971

41. Ondarza A J L, Bertonati M I, Blanco R. Tooth malalignments in Chilean children with Down Syndrome. Cleft Palate Craniofac J 1995; 32: 188-193.

42. Department of Health. NHS Dentistry: Options for Change. London: Department of Health, 2002.

43. Department of Health. Health and Social Care (Community Health and Standards) Bill. London: Department of Health, 2003.

44. Hedov $G$, Wikblad $K$, Anneren $G$. First information and support provided to parents of children with Down syndrome in Sweden: clinical goals and parental experiences. Acta Paediatrica 2002; 91 : 1344-1349. 